\title{
La Escuela Católica y el Enfoque de Capacidades Humanas: puntos de encuentro y reflexión ${ }^{1}$
}

\section{Catholic school and human capabilities approach: meeting and reflection topics}

\author{
Camilo Andrés Barrera Alvarado ${ }^{2}$ \\ Quihicha Hisca Iraca Vargas Salamanca ${ }^{3}$
}

\begin{abstract}
Resumen
El artículo presenta los avances de la primera parte de la investigación inter escuelas de la Unimonserrate: "Formulación del Proyecto Docente de la Escuela Católica, desde la experiencia del SEAB (Sistema Educativo de la Arquidiócesis de Bogotá). Propuesta a partir de la relación entre las prácticas educativas docentes en los distintos niveles de educación y la ampliación de capacidades humanas en los estudiantes". Se exploran los fundamentos y generalidades de la Escuela Católica, el rol del docente y el enfoque de las capacidades humanas centrales propuesto por Martha Nussbaum. Fruto de esa exploración se presentan los puntos de encuentro que permiten comprender la labor de la Escuela Católica desde la perspectiva del Enfoque de Capacidades $\mathrm{Hu}$ manas, los cuales constituyen las categorías de análisis iniciales para el desarrollo de la investigación.
\end{abstract}

Palabras clave: Escuela Católica; Enfoque de Capacidades Humanas; Docente. Libertad. Proyecto de vida..

\begin{abstract}
The article presents the first part of an Unimonserrate inter-school research: "Formulation of the Catholic School Teaching Project, from the SEAB experience (Archdiocese of Bogota Educative System). Proposal based on the relationship among teachers' educational practices at different levels of education and the expansion of human capabilities in students". It explores the foundations and generalities of the Catholic School, the role of the teacher, and the central human capabilities approach proposed by Martha Nussbaum. As the result of this exploration, points in common that allow us to understand the work of the Catholic School from the perspective of the Human Capabilities Approach are presented, which constitute the initial categories of analysis for the development of research.
\end{abstract}

Keywords: Catholic school; Human capabilities approach; Teacher. Freedom. Life Project.

\footnotetext{
${ }^{1}$ Artículo de Reflexión.

${ }^{2}$ Docente del programa de Trabajo Social de la Unimonserrate. Trabajador Social de la Fundación Universitaria Monserrate, Magíster en Estudios y Gestión del Desarrollo de la Universidad de La Salle. Correo: camilo.barrera@unimonserrate.edu.co

${ }^{3}$ Docente del programa de Trabajo Social de la Unimonserrate. Trabajadora Social de la Universidad Colegio Mayor de Cundinamarca, Especialista en Administración Pública de la Escuela Superior de Administración Pública, Maestría en Planeación para el Desarrollo de la Universidad Santo Tomás. Correo: iracavargas@unimonserrate.edu.co 


\section{Introducción}

La investigación "Formulación del Proyecto Docente de la Escuela Católica, desde la experiencia del SEAB. Propuesta a partir de la relación entre las prácticas educativas docentes en los distintos niveles de educación y la ampliación de capacidades humanas en los estudiantes", se encuentra en ejecución desde las Escuelas de Ciencias $\mathrm{Hu}$ manas y Sociales y de Educación de la Fundación Universitaria Monserrate siendo aprobada en la convocatoria institucional de investigaciones del primer semestre de 2016 y cuyo desarrollo está previsto entre el segundo semestre de 2016 y el segundo semestre de 2017, a cargo de tres docentes investigadores, dos del programa de Trabajo Social de la Escuela de Ciencias Humanas y Sociales y una de la Escuela de Educación ${ }^{4}$. Además, se cuenta con el apoyo de estudiantes de Trabajo Social auxiliares de investigación como modalidad de trabajo de grado.

El propósito de la primera etapa fue la contextualización de la investigación, la apropiación conceptual por parte del equipo y la identificación de categorías de análisis iniciales que podrán servir como orientadoras para el posterior proceso de recolección de la información. Fruto de este ejercicio, se presenta el artículo con el siguiente orden: 1) Presentación de la investigación, 2) Cuerpo del artículo: Conceptualización y Articulación, 3) Conclusiones: Horizontes para continuar el camino.

\section{Presentación de la investigación}

La investigación nace de la premisa, socialmente aceptada, de la importancia que tiene la educación en la posibilidad de que la persona supere las po-

\footnotetext{
${ }^{4}$ La propuesta fue formulada para tres investigadores, pero al momento no se había designado el investigador de la Escuela de Educación, el cual se integrará en la segunda fase del proyecto.
}

brezas (estudios como el de Spicker y otros (2009), reconocen que la pobreza no es solo económica sino diversa y multidimensional) que pueden presentarse en sus dinámicas sociales. Para que esto sea real, es necesario comprenderlo desde la complejidad del mundo social, es decir, la educación por sí misma no puede propiciar la superación de la pobreza, sino la educación en un contexto donde todos sus elementos (política, economía, ética, religión, etc.) y actores (Familias, Estado, Iglesia, Instituciones educativas, Empresas, etc.) estén profundamente comprometidos con ello.

Cada una de esas instituciones (familia, escuela, sociedad) asumen su rol desarrollando unas capacidades particulares y partir de sus propias circunstancias sociales e históricas. Concretamente en el caso de la Escuela, el servicio de la educación se presta desde la escolaridad, es decir, mediante el acompañamiento a la formación de la persona a lo largo de su vida (educación inicial, primaria, secundaria y superior, y esta última en pregrado, posgrado), tiempo durante el cual ofrecen los contenidos académicos a través de unas prácticas orientadas a la ampliación de capacidades de los sujetos participantes.

Esto lo reflejan las Instituciones Educativas en sus Proyectos Educativos Institucionales (en adelante PEI), y lo manifiesta el Sistema Educativo de la Arquidiócesis de Bogotá (en adelante SEAB) en su intencionalidad: "formar excelentes seres humanos, auténticos cristianos, verdaderos servidores de la sociedad" (SEAB, 2014, p.5), y lo concretan a través de todas y cada una de las mediaciones que utilizan, una de ellas, las relaciones docente-estudiante, esto es, las prácticas mediante las cuales el docente propicia en el estudiante el desarrollo del espíritu crítico, por lo que la docencia "se asume y desarrolla pedagógicamente como un proceso complejo y multidireccional, a través del cual se hace intercambio de conocimientos y de cosmovisiones, en un ambiente de respeto por 
la diferencia y por la rigurosidad en los argumentos" (PEI Unimonserrate, 2016, p. 12).

Por su parte, la Iglesia Católica comprende la educación como una de las múltiples maneras de desarrollar su labor evangelizadora: "La Escuela Católica entra de lleno en la misión salvífica de la Iglesia y particularmente en la exigencia de la educación a la fe", por lo que su proyecto "se define precisamente por su referencia explícita al Evangelio de Jesucristo, con el intento de arraigarlo en la conciencia y en la vida de los jóvenes, teniendo en cuenta los condicionamientos culturales de hoy" (La Escuela Católica, 9), y desde aquí, promueve la plenitud integral del hombre, es decir, su liberación de todo aquello que lo oprime, excluye y lo conduce a la muerte, lo cual constituye un punto de encuentro entre la Escuela Católica y el Enfoque de Capacidades Humanas: "pensar mediante las capacidades la dimensión emancipatoria de la educación y, por otro, juzgar con ellas la calidad o éxito educativo teniendo en cuenta la diversidad cultural y socio-económica del alumnado" (Cejudo, 2006, p.366). El educador, entonces, no sólo contribuye a la formación de la persona en conceptos teóricos, sino que proyecta e invita a asumir un estilo de vida integral, especialmente a través de su testimonio y de la relación que establece con todos y cada uno de los estudiantes, precisamente porque reconoce la docencia como un medio que contribuye a la realización plena de su estilo de vida:

A lo largo de la etapa evolutiva del alumno son necesarias relaciones personales con educadores significativos, y las mismas enseñanzas tienen mayor incidencia en la formación del estudiante si van impartidas en un contexto de compromiso personal, de reciprocidad auténtica, de coherencia en las actitudes, estilos y comportamientos diarios (Escuela Católica en los umbrales del tercer milenio, 18)
Las anteriores reflexiones permitieron el diseño de la propuesta investigativa. Como docentes de una institución que pertenece al Sistema Educativo de la Arquidiócesis de Bogotá, es importante comprender de qué manera los estudiantes que participan en sus distintos niveles de formación están ampliando sus capacidades para vivir dignamente y en libertad, más aún cuando el ser humano vive en contextos de desigualdad económica, injusticia social, pero, también, de nuevas comprensiones de la libertad y de múltiples maneras de relacionarse con lo trascendente:

Frente a esta «escuela paralela», se impone la presencia activa de la escuela que, mediante una educación sistemática y crítica, prepare a los jóvenes a un autocontrol, que los capacite para hacer opciones libres y conscientes frente a los mensajes que le presentan los medios de comunicación social. Es necesario enseñarles a someter tales mensajes a un juicio crítico personal, a ordenarlos en buenas síntesis y a integrarlos en su cultura humana y cristiana. (La Escuela Católica, 48)

Por lo anterior, el equipo decidió centrar su interés en la relación docente-estudiante, particularmente desde la perspectiva del primero de ellos, y se propuso responder a la siguiente pregunta de investigación ¿Mediante qué prácticas educativas los docentes del SEAB reconocen que promueven en los estudiantes la ampliación de capacidades humanas? A partir de las respuestas que se den a esta pregunta se podrá comprender: a) la relación entre las prácticas educativas en los distintos niveles de formación con la ampliación de capacidades de los estudiantes, y b) la identificación de los docentes, desde su particularidad y heterogeneidad, con la misión de la Escuela Católica y del SEAB, y desde allí c) formular estrategias que permitan atender la demanda institucional de formular el 
proyecto docente de la Escuela Católica a partir de la experiencia del SEAB.

Como objetivo general del proyecto se propuso: Formular el proyecto docente de la Escuela Católica desde la experiencia SEAB, en el marco del enfoque de las capacidades humanas, partiendo de las prácticas educativas de los docentes en los distintos niveles de formación, para ello se propusieron cuatro objetivos específicos, de los cuales el primero de ellos tiene relación expresa con el presente artículo: Identificar los postulados que permiten comprender a la Escuela Católica como un escenario de ampliación de capacidades de sus estudiantes, desde las prácticas educativas de sus docentes.

Una realidad del sistema educativo en general, y en la Escuela Católica no es la excepción, es que si bien se tiene en alta estima y reconocimiento el papel del docente, y esto se encuentra formulado en los documentos institucionales y las políticas, no se encuentran con facilidad las orientaciones metodológicas y estrategias por medio de las cuales las instituciones educativas puedan apoyar efectivamente la labor del docente, como lo constata un estudio realizado por la Universidad de la Sabana y el Ministerio de Educación de Colombia (2011): "es muy poco frecuente encontrar políticas, lineamientos o programas en los sistemas educativos para orientar el ingreso de los docentes recién egresados de las normales superiores, facultades de educación u otra facultad al contexto escolar" (p.7).

Reconociendo la realidad anterior, la complejidad de la sociedad, la misión de la Escuela Católica, y el papel del docente, se hace necesario identificar cuál es el proyecto docente de la misma, esto es, los lineamientos y estrategias que configuran las instituciones educativas de la Iglesia como un escenario propicio para el desarrollo humano del docente, y así, propiciar la ampliación de capacidades de los estudiantes de manera integral, desde la experiencia del SEAB, contribuyendo así al robustecimiento de las dimensiones evangelizadora y pedagógicaacadémica del Sistema.

Para ello, se diseñaron tres fases: en el primer momento (Contextualización) se desarrolló el marco teórico de la investigación comprendiendo la relación entre Escuela Católica y Capacidades humanas, especialmente desde la perspectiva del rol del docente; en segundo lugar (Recolección) se realizará la aproximación institucional a través de los PEI de cuatro instituciones del SEAB y de entrevistas a docentes; finalmente (Proyección), la triangulación de la información permitirá diseñar lineamientos y estrategias que gestarán el proyecto docente de la Escuela Católica, desde la experiencia del SEAB. Al momento de preparación del presente artículo, nos encontrábamos en el desarrollo de la fase uno, avances presentados a continuación.

\section{Cuerpo del artículo: Conceptualización y articulación}

\subsection{Conceptos clave}

En la primera fase, denominada contextualización, se identificaron los postulados que permiten comprender a la Escuela Católica como un escenario de ampliación de capacidades de sus estudiantes, desde las prácticas educativas de sus docentes, para lo cual se han explorado los siguientes conceptos: Escuela Católica, SEAB, Docente, Paradigma del Desarrollo Humano y Enfoque de Capacidades Humanas, los cuales se expondrán a continuación ${ }^{5}$.

${ }^{5}$ El concepto Prácticas educativas docentes se explorará en conjunto con el tercer investigador, para el primer semestre de 2017. 


\section{Escuela Católica}

La Escuela Católica, como parte de la institución eclesial, se entiende desde dos dimensiones: en primer lugar, desde su naturaleza, "todo su ser y su hacer quedan impregnados por la fe", es decir, no sólo responde a las necesidades culturales y sociales establecidas como fines de la educación en general, sino que "además tiene su finalidad específica, que consiste en constituir una comunidad escolar animada por el espíritu evangélico" (Bunge, 2001, p.4), por lo que sus dinámicas, como comunidad educativa, tienen características particulares:

La identidad de la escuela católica en cuanto comunidad educativa eclesial queda afianzada cuando se ha creado en ella un ambiente tal que en la cotidianidad de la tarea propia de cada uno de sus miembros ellos crecen en su adhesión a los valores del Evangelio, en su condición de discípulos de Cristo y en su conciencia misionera en el mismo espacio escolar y en su proyección más allá de esos límites. (Aguer, 2013, s.p.)

En segundo lugar, la Escuela Católica se entiende desde su formación canónica, es decir, "la vinculación de la escuela católica con la autoridad eclesiástica" (Bunge, 2001, p.4), que en el caso particular del SEAB corresponde al Arzobispo de la ciudad y los rectores de los Colegios Parroquiales y Unimonserrate, que son presbíteros con excepción del Liceo Sara Zapata y el Gimnasio Manuel María Camargo. Bunge indica tres estilos distintos de Escuelas Católicas, y para efectos de la investigación sólo se hará referencia al vinculado directamente con la autoridad eclesial. El rasgo distintivo de las Escuelas Católicas, es ser una comunidad educativa inspirada por el espíritu eclesial: "Por su propia naturaleza eclesial, la escuela católica debe ser una comunidad, alimentada por la Palabra de Dios y por los Sacramentos. Y por su propia función, debe ser una comunidad educativa” (Bunge, 2001, p.4).
Lograr la educación integral "con rostro eclesial" requiere de un proceso de reflexión que integre a los distintos actores que hacen parte de las Escuelas Católicas. Para esto, es necesario que cada uno de ellos reconozca y se comprometa decididamente con su labor, para lograr que las estrategias pedagógicas sean caracterizantes, transformantes, integradoras, ejemplarizantes y cualificantes (Delgado 2015), lo cual no implica, necesariamente que todos sus miembros profesen la fe católica (Bunge, 2001), puesto que, desde su identidad propia, la Escuela Católica camina en la realidad de la pluralidad religiosa y cultural contemporáneas, lo cual constituye un reto, pero también una posibilidad, para educar en un ambiente de libertad (libertad de expresión de la fe personal e institucional), en el que tanto la persona como la institución puedan expresar sus opciones de fe en un ambiente de comprensión y respeto, como una manera de atender a la integralidad del ser humano:

La escuela católica ve en su interior una presencia cada vez más relevante de alumnos de diferentes nacionalidades y confesiones religiosas; en muchos países del mundo, la mayoría de los estudiantes profesa un credo distinto y la cuestión del intercambio religioso se presenta ya ineludible. Para evitar clausurarse en un "identicismo" con fin en sí mismo, un proyecto educativo debe contar con el creciente grado de plurireligiosidad de la sociedad, y con la consiguiente necesidad de saber conocer y dialogar con las distintas creencias y con los no creyentes. (Educar al Diálogo intercultural en la Escuela Católica, 55)

Lo anterior supone en la acción evangelizadora de la Iglesia, y por supuesto al interior de las Escuelas Católicas, una actitud de apertura y disponibilidad al diálogo pues se desarrolla en medio de la complejidad de la sociedad contemporánea que, en el caso particular de Bogotá, se caracteriza por tres 
aspectos: "la transición socio-cultural y religiosa, la pluralidad cultural y las desigualdades sociales" (Vicaría de Evangelización, 2014, p.17), según se logra identificar en el Plan de Evangelización de la Arquidiócesis de Bogotá.

En esta complejidad se va construyendo el ser humano, en un dinamismo que hace necesario reconocer ese nuevo ser emergente, ante el cual el mensaje evangelizador es constante, y se expresa en el Plan Arquidiocesano de Evangelización (Vicaría de Evangelización, 2014) de la siguiente manera: Un ser: a) creado a imagen y semejanza de Dios, b) libre, c) social, d) cultural llamado a la transformación de la historia, y e) afectado por la condición histórica de la humanidad pecadora (pp. 51-57).

Si la Escuela Católica es el dispositivo mediante el cual la Iglesia desarrolla la labor evangelizadora desde la educación (como una de las distintas herramientas con las que cuenta para hacerla), es claro que ella, además de impartir una suerte de conocimientos teóricos particulares, y de desarrollar unas habilidades básicas como saber leer, escribir, relacionarse con otros, asume como eje central de su formación la persona en sus distintas dimensiones, y se orienta a permitir que todos los miembros de la comunidad educativa encuentren en ella un escenario para su desarrollo humano, razón por la cual la Escuela Católica entiende su educación como integral.

\section{El Sistema Educativo de la Arquidiócesis de Bogotá}

El escenario concreto en el que se desarrolla el estudio serán tres Colegios Parroquiales (de diecinueve) y la Institución de Educación Superior que conforman el Sistema Educativo de la Arquidiócesis de Bogotá, el cual nació en 2013, con el fin de articular la labor de los Colegios Parroquiales de esta iglesia particular "en un sistema que, respetando los énfasis o contextos de cada colegio, les permitiera una identidad más corporativa y diocesana que parroquial" (SEAB, 2014, p.4), incluyendo también, desde 2014, a la Fundación Universitaria Monserrate-Unimonserrate, con la que amplía la oferta educativa a todos los niveles.

En las instituciones del SEAB se diseñan ambientes que brindan oportunidades a sus estudiantes y demás miembros de la comunidad educativa, para llegar a ser personas integrales, éticas, sensibles y solidarias con sus semejantes; creativas, con actitud y competencia critico constructiva; con capacidad para mirarse a sí mismas y estar abiertas a su propia transformación. (SEAB, 2014, p.5)

Su horizonte misional, como se indicó en la introducción, es contribuir a que, en todas las instituciones a él vinculadas, en sus distintos niveles educativos, se formen "excelentes seres humanos, auténticos cristianos, verdaderos servidores de la sociedad", para lo cual busca la articulación de las experiencias y saberes de los distintos Colegios y de la Fundación Universitaria.

El centro del Sistema, como de la filosofía de la Escuela Católica, es la persona que "construye su propio proyecto de vida a través de la interacción con su contexto, que es medio para hacerse sujeto" (SEAB, 2014, p.5), y en este sentido es una experiencia de libertad y de autenticidad:

En el ejercicio de la misión evangelizadora es muy importante ayudar a las personas, especialmente a los jóvenes, a tomar conciencia de los dinamismos propios que los habitan y a interpretarlos en la perspectiva de la vocación divina que constituye en la intimidad de su ser. Es necesaria una pedagogía que contribuya al planteamiento de las cuestiones vitales del ser humano, pues, de modo contrario, se corre el riesgo de que el Evangelio caiga en el vacío y no sea valorado. (Vicaría de Evangelización, 2014, p. 50) 
El Sistema, desde el servicio de la educación, se articula al Plan de Evangelización de la Arquidiócesis de Bogotá, cuyo nuevo paradigma de evangelización se caracteriza, entre otras cosas por entender su pedagogía en clave misionera, "que supera las tentaciones del siempre se ha hecho así, del cambiar por cambiar sin horizonte y sin sentido, del activismo y del empirismo" (Vicaría de Evangelización, 2014, p. 91), es decir, "una Iglesia enviada, en salida", lo que implica

la superación de esa pedagogía uniforme, única e igual para todos, que no reconoce, ni se apropia de las diferentes situaciones personales y comunitarias frente a la fe y el Evangelio. En términos de Aparecida, se requiere una pedagogía respetuosa de los procesos personales y los ritmos comunitarios, que requiere itinerarios diversificados, continuos y graduales (Vicaría de Evangelización, 2014, p. 93).

Comprender la pedagogía en clave misionera permite identificar lo que implica la centralidad de la persona en el Plan de Evangelización y en el Sistema Educativo arquidiocesanos:

La pedagogía misionera pide, como novedad, ofrecer variedad y multiplicidad en los itinerarios, que acompañen a las personas en su situación y en su proceso de apropiación personal y comunitaria de la fe. [...] Personas diversas han de encontrar caminos diversos, abiertos y plurales, respetuosos de su situación, de su ritmo, de su caminar, de su proceso. [...] No se puede esperar que todos se sientan motivados por la misma mediación. [...]

Lo anterior exige una pedagogía misionera, plural y heterogénea, distinta de la homogeneidad característica, hasta el día de hoy, en la arquidiócesis. [...]

Pastoral que se caracteriza por una presencia abierta, dialógica, propositiva y significativa en los espacios humanos donde transcurre la vida. [...]. (Vicaría de Evangelización, 2014, pp. 95-96)

\section{El docente en la Escuela Católica}

A partir de lo anterior, en la Escuela Católica se reconoce el valor que tiene el docente en el proceso de formación integral de la persona que participa en sus instituciones, y así mismo adquiere un rasgo distintivo de la escuela en general. Es ante todo un educador, un "formador de hombres" (El laico católico, testigo de fe en la Escuela, 16), que no se centra exclusivamente en la transmisión de un conjunto de conceptos disciplinares específicos, sino que con su ejercicio construye humanidad, pues escribe "sobre el alma misma de los hombres" (La Escuela católica en los umbrales del tercer milenio, 16). Esto permite pensar que el docente debe contar con ciertas características particulares, tanto personales como profesionales, y que encuentre en su institución un escenario que le permita potenciarlas positivamente en su relación con los estudiantes:

El único modo de que toda la enseñanza sea una verdadera escuela de la fe en la escuela católica es que el maestro sea un hombre de fe, ya que la síntesis entre la cultura y la fe se realiza por la armonía orgánica de la fe y la vida en la persona misma del maestro. Esto no excluye que puedan actuar profesores no católicos en algunas disciplinas (no, claro está, en la enseñanza de la religión católica), siempre que cumplan con el requisito de la "recta doctrina e integridad de vida”. (Bunge, 2001, p.5)

Es decir, si la Iglesia se propone ofrecer una formación integral a sus estudiantes, la integralidad debe ser un aspecto constituyente del ser y del quehacer docente sin que esto quiera decir unifor- 
midad $\mathrm{u}$ homogeneidad de pensamiento.

De lo anterior se puede establecer una estrecha relación -no causal, ni lineal- entre la excelencia de los estudiantes y la excelencia de los docentes, que estará mediada no sólo por la cualificación académica -que es importante y necesaria- sino, también, en la vivencia de la libertad, la autenticidad y el servicio, de manera que puedan acompañar a los estudiantes en sus procesos de crecimiento personal. Es importante no olvidar, sin embargo, que los docentes, seres humanos inmersos en la historia, también se encuentran en permanente autoconstrucción, por tanto, la excelencia no puede constituir un a priori sino una invitación a alcanzarlo en relación, por cuanto la Escuela Católica, también, ha de constituir un escenario propicio para que los docentes se desarrollen integralmente, como lo indica la Congregación para la Educación Católica: "A los docentes y a los dirigentes se les pide mucho. (...) Para poder responder a tales expectativas es necesario que dichas tareas no se dejen a la responsabilidad individual, sino que se ofrezca un adecuado apoyo a nivel institucional" (Educar hoy y mañana. Una pasión que se renueva, 17).

\section{El Enfoque de las Capacidades Humanas Centrales}

Se escogió el Enfoque de Capacidades Humanas como eje paradigmático que permita articular la importancia de la educación y la centralidad de la persona en un ámbito de libertad y autenticidad que favorezcan la vivencia de la fe, el sentido crítico, y la capacidad de escoger lo que contribuye a la dignidad humana, dentro de un abanico de posibilidades.

En el ejercicio del ser y quehacer en el que cada uno de los individuos se ven enfrentados todos los días, hay un aporte importante que hace Nussbaum, quien desde la perspectiva del desarrollo humano hace claridad en que la capacidad significa 'oportunidad de seleccionar' (Nussbaum,
2012, p. 45) dentro de un abanico de posibilidades que cada individuo debe tener. Es decir, hablar de Desarrollo Humano implica hablar de libertad: "promover capacidades es promover áreas de libertad, lo que no es lo mismo que hacer que las personas funcionen en un determinado sentido" (Nussbaum, 2012, p. 45), y precisamente la educación sería el servicio por medio del cual los Estados, y en el caso particular también la Iglesia - sin que se confundan las funciones y el papel que cada una de estas instituciones sociales tiene por sus naturalezas particulares -, promueven estas áreas de libertad. Es importante comprender con claridad esta concepción de capacidad, pues es pertinente diferenciarla de otras comprensiones del mismo término, que pueden implicarse, pero no constituyen el eje del estudio.

Para ello, Nussbaum propone el siguiente marco conceptual: como funcionamiento, comprende la "realización activa de una o más capacidades" (Nussbaum, 2012, p. 44), por ejemplo, celebrar la fe católica a través de los sacramentos, y pueden constituir la traducción de las capacidades, las cuales, entendidas como ámbitos de libertad y de elección, podrían ser, por ejemplo, la capacidad de vivir la fe, reconociendo distintas maneras de hacerlo: "Esta preferencia por las capacidades está ligada a la cuestión del respeto a una pluralidad de visiones religiosas y laicas de la vida diferentes" (Nussbaum, 2012, p.45). Profundizando, distingue entre capacidades internas $y$ capacidades combinadas. Las primeras son individuales y hacen referencia a "rasgos y aptitudes entrenadas y desarrolladas, en muchos casos con el entorno social, económico, familiar y político" (Nussbaum, 2012, p.41), es decir son capacidades en estado de madurez; las segundas son "la suma de las capacidades internas y las condiciones sociales/políticas/económicas en las que puede elegirse realmente el funcionamiento de aquellas" (Nussbaum, 2012, p.42). Finalmente aclara que las 
capacidades internas no son innatas en la persona, estas son las capacidades básicas, que posteriormente pueden madurar, formarse, y llegar a ser capacidades internas.

En medio de esta pluralidad, que en ocasiones puede desembocar en un relativismo extremo, Nussbaum se pregunta ¿qué capacidades priorizar?, y al presentar su respuesta indica que todo depende del fin que se persiga, y esto no se puede hacer con base en el concepto de capacidades en sí mismo, sino que debe involucrar otros, como dignidad - que reconoce que es "una idea poco precisa y que hay que dotar de contenido situándose en una red de nociones relacionadas" (Nussbaum, 2012, p. 50)-, que está estrechamente relacionado con conación activa, es decir, ser agente (capacidad de actuar del individuo), y que podría vincularse con la capacidad básica (inherente al ser humano). En este sentido, y observando la complejidad que rodea el hablar de un enfoque de capacidades, la autora opta por definir que, en su versión,

el enfoque de las capacidades se centra en la protección de ámbitos de libertad tan cruciales que su supresión hace que la vida no sea humanamente digna. Cuando una libertad no es tan trascendental, su regulación depende ya del funcionamiento corriente del proceso político. A veces, es evidente que una determinada capacidad tiene una relevancia central en ese sentido: el mundo ha alcanzado un consenso, por ejemplo, en torno a la importancia de la educación primaria y secundaria. [...] No son pocos los casos que pueden no estar claros durante mucho tiempo: siglos y siglos se tardó, por ejemplo, en entender que el derecho de una mujer a negarse a mantener relaciones sexuales con su marido es un derecho crucial de su integridad física. Lo que debe suceder en esos casos es que el debate correspondiente tenga lugar y que cada interviniente en él exponga argumentos que intenten mostrar que una libertad dada es inherente a la idea de dignidad humana. (Nussbaum, 2012, p. 52)

Lo anterior permite pensar los siguientes postulados: Primero, las instituciones educativas están en capacidad de hacer sus propias opciones y ofrecerlas a la comunidad, para que las familias escojan, a su vez, las que consideran más convenientes. Segundo, las instituciones educativas de definir sus currículos, en concordancia con las directrices políticas del Estado - como máximo responsable encargado de promover la educación en el país pero también, en concordancia con las opciones filosóficas, éticas, morales y de fe de la institución. Por último, la educación está estrechamente articulada con el ciclo vital de la persona, lo que implica reconocer las capacidades de la persona en cada etapa y ofrecer unos escenarios que promuevan la ampliación de dichas capacidades en dichos momentos, pues esto preparará al individuo para el desarrollo de sus capacidades posteriores: " $\mathrm{La}$ de los niños es, evidentemente, una situación distinta: exigirles ciertas formas de funcionamiento (como, por ejemplo, la educación obligatoria) es defendible como preludio necesario de la capacidad adulta" (Nussbaum, 2012, p.46).

Nussbaum define diez capacidades centrales que deben constituir el interés primordial de los gobiernos para garantizar que una vida se desarolle acorde con la dignidad humana, las cuales se transcriben a continuación: 
Tabla 1. Capacidades Humanas Centrales propuestas por Martha Nussbaum

\begin{tabular}{|c|c|}
\hline & Conceptualización \\
\hline$\frac{0}{\frac{0}{9}}$ & $\begin{array}{l}\text { Poder vivir hasta el término de una vida humana de una } \\
\text { duración normal }\end{array}$ \\
\hline 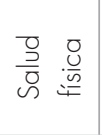 & $\begin{array}{l}\text { Poder mantener una buena salud, incluida la salud } \\
\text { reproductiva; recibir una alimentación adecuada; disponer } \\
\text { de un lugar apropiado para vivir. }\end{array}$ \\
\hline 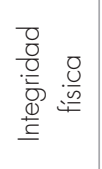 & $\begin{array}{l}\text { Poder desplazarse libremente de un lugar a otro; estar protegidos } \\
\text { de los ataques violentos, incluidas las agresiones sexuales y } \\
\text { la violencia doméstica; disponer de oportunidades para la } \\
\text { satisfacción sexual y para la elección en cuestiones reproductivas. }\end{array}$ \\
\hline 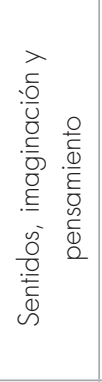 & $\begin{array}{l}\text { Poder utilizar los sentidos, la imaginación, el pensamiento y el } \\
\text { razonamiento y hacerlo de un modo "verdaderamente humano", un } \\
\text { modo formado y cultivado por una educación adecuada que incluya } \\
\text { la alfabetización y la formación matemática y científica básica. } \\
\text { Poder usar la imaginación y el pensamiento para la experimentación } \\
\text { y la producción de obras y actos religiosos, literarios, musicales o } \\
\text { de índole parecida, según la propia elección. Poder usar la propia } \\
\text { mente en condiciones protegidas por las garantías de la libertad de } \\
\text { expresión políiica y artística, y por la libertad de la práctica religiosa. }\end{array}$ \\
\hline 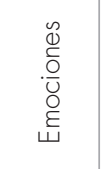 & $\begin{array}{l}\text { Poder sentir apego por cosas y personas externas a nosotras y } \\
\text { nosotros mismos; poder amar a quienes nos aman y se preocupan } \\
\text { por nosotros, y sentir duelo por su ausencia, en general, poder } \\
\text { amar, apenarse, sentir añoranza, gratitud e indignación justificada. }\end{array}$ \\
\hline 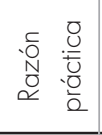 & $\begin{array}{l}\text { Poder formarse una concepción del bien y reflexionar críticamente } \\
\text { acerca de la planificación de la propia vida (Protección de la } \\
\text { libertad de conciencia y de observancia religiosa). }\end{array}$ \\
\hline \multirow[b]{2}{*}{ 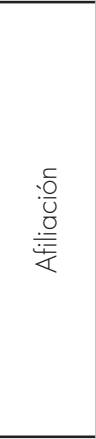 } & $\begin{array}{l}\text { a) Poder vivir con y para los demás, reconocer y mostrar } \\
\text { interés por otros seres humanos, participar en formas } \\
\text { diversas de interacción social; ser capaces de imaginar la } \\
\text { situación de otro u otra. }\end{array}$ \\
\hline & $\begin{array}{l}\text { b) Disponer de las bases sociales necesarias para que } \\
\text { no sintamos humillación y sí respeto por nosotros mismos; } \\
\text { que se nos trate como seres dignos de igual valía que los } \\
\text { demás. Esto supone introducir disposiciones que combatan } \\
\text { la discriminación por razón de raza, sexo, orientación } \\
\text { sexual, etnia, casta, religión u origen nacional. }\end{array}$ \\
\hline 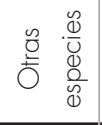 & $\begin{array}{l}\text { Poder vivir una relación próxima y respetuosa con los } \\
\text { animales, las plantas y el mundo natural. }\end{array}$ \\
\hline$\stackrel{\circ}{\stackrel{\circ}{D}}$ & Poder reír, jugar y disfrutar de actividades recreativas. \\
\hline \multirow{2}{*}{ 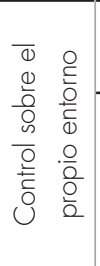 } & $\begin{array}{l}\text { a) Político. Poder participar de forma efectiva en las } \\
\text { decisiones políticas que gobiernan nuestra vida. }\end{array}$ \\
\hline & $\begin{array}{l}\text { b) Material. Poder poseer propiedades (tanto muebles como } \\
\text { inmuebles) y ostentar derechos de propiedad en igualdad } \\
\text { de condiciones con las demás personas; tener derecho a } \\
\text { buscar trabajo en un plano de igualdad con los demás. }\end{array}$ \\
\hline
\end{tabular}

Nota. Fuente: Nussbaum, Martha C. (2012, pp. 53-55).
La autora aclara con énfasis que las capacidades están dirigidas a la persona individual, y sólo indirectamente a los colectivos: "estipula que el objetivo es producir capacidades para todas y cada una de las personas", lo cual es necesario tener claro para tomar decisiones políticas; y más adelante añade "tampoco podemos desplazar este foco de atención normativo sobre el individuo hacia otros terrenos alegando algo tan obvio como que las personas se identifican a veces con colectivos que los engloban" (Nussbaum, 2012, p. 55). Así mismo, indica que las capacidades son irreductibles entre sí, es decir no se puede compensar una con otra, pues tienen un valor intrínseco en sí mismas, pero sí destaca que dos tienen una presencia dominante: la afiliación y la razón práctica, pues "cuando las otras están presentes de manera acorde con la dignidad humana, esas dos están entretejidas en ellas" (Nussbaum, 2012, p. 59), dado que estas constituyen una manifestación del ejercicio de la libertad, fundamental en este enfoque.

\subsection{Articulación Escuela Católica - Docente - Enfoque De Capacidades Humanas}

El proceso de revisión documental reflejado en los apartados anteriores, permite al equipo vislumbrar algunos puntos de encuentro entre los principios de la Escuela Católica y el Enfoque de Capacidades Humanas. Estos puntos de articulación, y las retroalimentaciones mutuas que surjan incluso de los puntos de desencuentro, leídos desde la intencionalidad del papel del docente, permitirán vislumbrar algunos aspectos que pueden constituir las categorías de análisis para identificar las prácticas educativas docentes de la Escuela Católica que permiten que los estudiantes, en los distintos niveles de formación, amplíen sus capacidades humanas y opten por una vida acorde con la dignidad humana, entendida aquí como la ple- 
nitud del ser humano querida por Dios, todo desde la experiencia particular del Sistema Educativo Arquidiocesano.

\section{Punto de partida: La centralidad de la persona humana.}

El primer punto de encuentro es que ambos, tanto la Escuela Católica, como el Enfoque de las Capacidades están centrados en la persona humana, en que esta construya su proyecto de vida en libertad y autenticidad, y de esta manera promueva que los otros construyan sus propios proyectos de vida de la misma manera. Para la Escuela Católica, desde la doctrina de la Iglesia, la capacidad para construir el proyecto de vida se deriva de la condición creatural del ser humano, es decir, ser creado por Dios, sujeto a un plan salvífico, y la plenitud de la creatura se comprende en cuanto cumple el propósito para el cual ha sido creada (voluntad de Dios).

\section{La libertad, fundamento del proyecto de vida.}

Pensar en la capacidad de construir su proyecto de vida, implica reconocer el papel de la libertad, la cual adquiere características particulares que se derivan de la comprensión de persona mencionada en el párrafo anterior. En efecto, ambas miradas contemplan la libertad como aspecto primordial en la plenitud humana. Para la doctrina católica, Cristo ha venido a liberar al hombre de toda opresión que aliena, que lo aleja de la voluntad del Creador que quiere que sea plenamente humano, y lo hizo a través de la plena obediencia a la voluntad del Padre. De la misma manera, la libertad se comprende en esa capacidad que tiene el ser humano para conocer el plan de Dios y adherirse en fidelidad, en medio de otras opciones que pueden no llevar a la plenitud. Para el Enfoque de Capacidades Humanas, por su parte, la capacidad es la oportunidad de elegir entre una multiplicidad de opciones, que se opone a no poder escoger y limitarse a una única posibilidad, sino a conocer las opciones críticamente, y optar por las que contribuyen de mejor manera a vivir dignamente.

Estas dos miradas acerca de la libertad no se oponen, sino que se pueden complementar entre sí: ser auténtico cristiano, en esencia, es un acto de libertad, donde la persona opta por vivir de acuerdo con una apuesta de fe concreta, que abarca la integralidad de su vida, y esto lo hace críticamente, es decir, comprendiendo el profundo valor que hay en esa opción y que le mueve a escogerla. Puede afirmarse que este fue el papel de Jesucristo reflejado en los Evangelios: criticó fuertemente las concepciones políticas y religiosas de su tiempo precisamente porque habían descuidado la centralidad de la persona ("el sábado se hizo para el hombre, no el hombre para el sábado", Marcos 2,27), y le habían impuesto cargas contrarias a los valores del reino ("Atan fardos pesados, difíciles de llevar, y se los cargan en la espalda a la gente, mientras ellos se niegan a moverlos con el dedo", Mateo 23,4), y en cambio ofreció su propia vida como modelo al que todos pueden acudir ("Vengan a mí, los que están cansados y agobiados, y yo los aliviaré. Carguen con mi yugo y aprendan de mí, que soy tolerante y humilde de corazón, y encontrarán descanso para su vida. Porque mi yugo es suave y mi carga ligera", Mateo 11,28) para alcanzar la plenitud, que radica en el cumplimiento de la voluntad de Dios ("No todo el que me diga: ¡Señor, Señor!, entrará en el reino de los cielos, sino el que haga la voluntad de mi Padre del cielo", Mateo 7,21).

\section{La dignidad humana, marco conceptual para comprender la libertad}

La libertad, como capacidad de escoger, puede estar sujeta a relativismos en los que todo vale, por lo que es necesario que sea comprendida dentro de un marco conceptual de la dignidad humana, el cual no es unívoco, y que para el caso particular de la Iglesia Católica se construye desde la riqueza 
de la interpretación bíblica y el Magisterio de la Iglesia, respondiendo a cada momento particular de la historia, como lo indicó el Concilio Vaticano II en su constitución pastoral:

Para cumplir esta misión, es deber permanente de la Iglesia escrutar a fondo los signos de la época e interpretarlos a la luz del evangelio, de forma que, acomodándose a cada generación, pueda la Iglesia responder a los perennes interrogantes de la humanidad sobre el sentido de la vida presente y de la vida futura y sobre la mutua relación de ambas. Es necesario por ello conocer y comprender el mundo en que vivimos, sus esperanzas, sus aspiraciones y el sesgo dramático que con frecuencia le caracteriza. (GS 4)

Se puede afirmar, entonces, que dentro de las distintas ofertas educativas que se articulan a los sistemas educativos de los países la Iglesia Católica tiene la propia, que, además de los contenidos regulares, ofrece una concepción del ser humano y una comprensión de la dignidad humana que debe ser transmitida a los estudiantes de las Escuelas Católicas, como manera de entender la labor evangelizadora. Al ser una oferta entre varias, debe caracterizarse por permitir el diálogo con las demás, comprender la riqueza propia y la de las otras, anunciar con fuerza la Buena Noticia que responda a los anhelos más profundos del corazón de los seres humanos que se van integrando a sus instituciones y que presentan nuevas demandas propias de las épocas, denunciar aquellos contrarios a la dignidad humana, y todo en un lenguaje caracterizado por la primacía del Amor, como signo propio de las relaciones entre la comunidad educativa ("Les doy un mandamiento nuevo, que se amen unos a otros como yo los he amado: ámense así unos a otros. En esto conocerán todos que son mis discípulos, en el amor que se tengan unos a otros", Juan 13,34-35), y sobre todo el sig- no hacia toda la sociedad y aquellas comunidades que pueden pensar distinto ("Si ustedes aman sólo a quienes los aman, ¿qué premio merecen? También hacen lo mismo los recaudadores de impuestos. Si saludan sólo a sus hermanos, ¿qué hacen de extraordinario? También hacen lo mismo los paganos. Por tanto, sean perfectos como es perfecto el Padre de ustedes que está en el cielo", Mateo 5,46-48).

\section{La dimensión liberadora de la educación}

La Escuela Católica, desde su propia opción, constituye una apuesta orientada al cumplimiento de los fines de la educación. La institución educativa tiene la posibilidad de propiciar el desarrollo del espíritu crítico frente a los sistemas sociales, políticos, económicos y religiosos, entre otros, como lo propone el paradigma del Desarrollo Humano, perspectiva desde la que se plantea el Enfoque de Capacidades Humanas:

la teoría del desarrollo de Sen aborda la educación desde una óptica distinta al no concebir el desarrollo como un medio para el crecimiento económico, la industrialización, o algún otro objetivo, sino como un fin en sí mismo definido como expansión de la libertad humana mediante la capacidad para llevar la vida que cada uno tenga razones de elegir. (Cejudo, 2006, p. 368)

Para que lo anterior se lleve a cabo, es importante que la Escuela, en los distintos niveles de formación, comprenda su valor fundamental en la ampliación de capacidades de los seres humanos que constituyen su comunidad educativa, esto es, en el desarrollo de la libertad y la autenticidad para vivir de manera acorde con la dignidad humana. Pensando en los estudiantes, es importante que articule sus planes curriculares no sólo en torno a los contenidos, sino a reconocer aquellas capacidades propios de la etapa vital que es importante desarrollar de cara a contribuir a que sus partici- 
pantes lleguen a ser, como se lo propuso el SEAB, "excelentes seres humanos, auténticos cristianos y verdaderos servidores de la sociedad". Reconocer esto, como institución, contribuye a enriquecer la comprensión de la importancia de la labor educativa. Al respecto, un listado de diez capacidades humanas centrales, como el propuesto por Martha Nussbaum, podría ser sugerente para identificar las capacidades primordiales por etapa vital, o cómo se están viviendo todas ellas en los entornos de aprendizaje.

De esta manera, se puede entender la importancia de la Escuela Católica como escenario de evangelización, y en la experiencia particular de Bogotá, las instituciones de educación católica, unas de ellas que integran el SEAB, se comprenden como un espacio importante para dar vida al Plan de Evangelización de la Arquidiócesis de Bogotá.

Por esto, es importante que las instituciones de la Escuela Católica se comprometan decididamente en el acompañamiento a sus docentes, de manera que en sus instituciones estos encuentren un escenario para: a) articularse de modo que entre todos promuevan eficaz y eficientemente la ampliación de capacidades de los estudiantes, y b) ampliar sus propias capacidades, cualificarse profesionalmente y enriquecer sus propios proyectos de vida, desde la diversidad que los puede caracterizar, pero con la certeza de un encuentro personal con Jesucristo.

\section{Conclusiones: Horizontes para continuar el camino}

Las reflexiones aquí consignadas constituyen los puntos de partida que orientarán las indagaciones para identificar qué prácticas educativas de los docentes del SEAB contribuyen a la ampliación de las capacidades de los estudiantes, y a partir de ahí, proponer el proyecto docente de la Escuela Católica, donde cada docente pueda encontrar no sólo las exigencias sino, sobre todo las herramientas, estrategias e incentivos que les permitan comprender y vivir su realidad como excelentes, auténticos y verdaderos educadores. Estos puntos de partida, junto con la comprensión conceptual de las prácticas educativas docentes, serán las guías hermenéuticas que permitan identificar los lineamientos que permitan configurar proyectos docentes que, fieles a los postulados de la Escuela Católica, pero encarnados en las características propias de las instituciones educativas del SEAB, permitan la construcción de proyectos de vida orientados a la excelencia, la autenticidad y el servicio, tanto en sus docentes como en sus estudiantes.

Los estudiantes que llegan a las aulas de las instituciones del SEAB son seres libres, y su dignidad las hace los protagonistas centrales de la labor educativa. Son seres, además, con historias, con vivencias, con aprendizajes previos, ante los cuales el Colegio o la Universidad se presentan, desde los postulados teóricos, como escenarios liberadores, ante las distintas propuestas que pueden convertirse en opresoras, o que pueden menoscabar la posibilidad de construir proyectos de vida escogiendo el estilo de vida que se considera valiosa. Sin embargo, es necesario escuchar las voces de los docentes, pues en su día a día pueden evidenciar o no si este ideal se está cumpliendo, son ellos y ellas quienes diariamente están pensando y repensando, en sintonía con unos principios orientadores, las mejores maneras de gestar esta liberación, pero no de manera general, sino situada, es decir, desde las características particulares de los sujetos participantes.

Lo anterior lleva a pensar que, si bien existen ideales generales para la educación tanto de la perspectiva católica como desde el enfoque de las capacidades humanas, el proyecto docente tiene que construirse de forma contextualizada, es decir, desde las realidades propias del nivel educativo (inicial, primaria, bachillerato y superior), y del tipo de institución (colegio, universidad), los cuales tienen 
que ser escenarios donde la persona de los y las docentes gesten su propia liberación, $y$, de esta manera lleguen a ser ejemplo para sus estudiantes.

\section{Referencias}

Aguer, H. (2013). La Identidad de la Escuela Católica. Conferencia inaugural del Congreso Provincial de Educación Católica de Entre Ríos. Concepción del Uruguay, 25 de abril de 2013. Recuperado de http://arzolap.org.ar/homilias2013/laidentidaddelaescuelacatolica.html

Bunge, A. (2001) ¿Qué es la escuela católica? En Anuario Argentino de Derecho Canónico (1) 77-92. Recuperado de: https://www.google.com.co/url?sa=t\& $\mathrm{rct}=\mathrm{j} \& \mathrm{q}=\& \mathrm{esrc}=\mathrm{s} \&$ source $=$ web \&cd=1\&cad=rja\& uact $=8 \&$ ved $=0$ ahUKEwiAxPjSq8LSAhWpilQKH QQyDMUQFggaMAA\&url=http $\% 3 \mathrm{~A} \% 2 \mathrm{~F} \% 2 \mathrm{Fw}$ ww.awbunge.com.ar\%2FAADC2001-2.doc\&usg= AFQjCNE7WdmyQbHW9njenC3fRx8AYMA-8w

Cejudo, C. (2006). Desarrollo humano y capacidades. Aplicaciones de la teoría de las capacidades de Amartya Sen a la educación. Revista Española de Pedagogía,(234), 365-380.

Congregación para la Educación Católica. (2014). Educar hoy y mañana una pasión que renueva (Instrumentum Laboris). Recuperado de http://www.vatican.va/roman_curia/congregations/ccatheduc/ documents/rc_con_ccatheduc_doc_20140407_ educare-oggi-e-domani_sp.html

(2007) Educar juntos en la Escuela Católica. Misión compartida de personas consagradas y fieles católicos. Recuperado de http://www.vatican.va/ roman_curia/congregations/ccatheduc/documents/rc_con_ccatheduc_doc_20070908_educare-insieme_sp.html

(1997) La Escuela Católica en los umbrales del tercer milenio. Recuperado de http://www.vatican.va/roman_curia/congregations/ccatheduc/ documents/rc_con_ccatheduc_doc_27041998_ school2000_sp.html
(1982) El laico católico, testigo de fe en la Escuela. Recuperado de http://www.vatican.va/roman_cu$\mathrm{ria} /$ congregations/ccatheduc/documents/rc_con_ ccatheduc_doc_19821015_lay-catholics_sp.html

(1977) La Escuela Católica. Recuperado de http://www.vatican.va/roman_curia/congregations/ccatheduc/documents/rc_con_ccatheduc_ doc_19770319_catholic-school_sp.html

Concilio Vaticano II. (1965). Constitución Pastoral Gaudium et Spes. Sobre la Iglesia en el mundo actual. Recuperado de: http://www.vatican.va/archive/hist_councils/ii_vatican_council/documents/ vat-ii_const_19651207_gaudium-et-spes_sp.html

Delgado, D. (2015). Los valores en la escuela. ¿Un protocolo de obediencia a la ley o un camino de humanización? Revista virtual Nuevas búsquedas - SEAB, 2015. (1), 22-36. Recuperado de: http://docplayer. es/31295935-1-revista-virtual-nuevas-busquedasseab.html

Fundación Universitaria Monserrate. (2016). Proyecto Educativo Institucional - PEI - Proyección, cercanía, cuidado. Bogotá: Unimonserrate.

Nussbaum, M. (2012). Crear capacidades: propuesta para el desarrollo humano. Barcelona: Paidós.

Sistema Educativo de la Arquidiócesis de Bogotá. (2014). Una propuesta: Un camino. Documento de Trabajo. Bogotá: SEAB.

Spicker, P., Alvarez, S. y Gordon, D. (2009). Un glosario Universal. Buenos Aires: Consejo Latinoamericano de Ciencias Sociales - CLACSO.

Universidad de La Sabana - Ministerio de Educación Nacional. (2011). Estrategia de acompañamiento docentes nóveles. BID - Proyecto Sistema Integrado de Formación de Capital Humano. Chía, Cundinamarca, Colombia.

Vicaría de Evangelización. (2014). Plan de Evangelización. El paradigma de evangelización de la Arquidiócesis de Bogotá. Documento No 5 . Fundamentos teológicos y pastorales. Bogotá D.C. 